\title{
Explaining Risk Perception of Climate Change in Indonesia through Cultural Dimension of Uncertainty Avoidance, Collectivistic, and Long-term Orientation
}

\author{
Victor Matanggaran ${ }^{1}$, Jan M. Gutteling ${ }^{2}$ \\ ${ }^{I}$ Macanga Institute, Indonesia \\ ${ }^{2}$ University of Twente, Netherlands
}

\begin{abstract}
Risk perception of climate change has believed to be the first step to tackle climate change problems globally. There are many factors to cause people to be aware of climate change risks. However, research on cultural dimensions has rarely been done. This research examines the correlation of cultural dimension uncertainty avoidance, collectivistic, and long-term orientation with risk perception of climate change. The research was conducted in Indonesia as the country with a high score in uncertainty avoidance, collectivistic, and long-term orientation. Data was collected using an online survey Qualtrics and shared in several cities in Indonesia such as the capital city Jakarta, Riau (Sumatera), South Sulawesi, West Sulawesi, West Java, East Java, and Jogjakarta (Java). Hierarchical multiple regression analysis was conducted on 562 respondents in the survey and found that risk perception of climate change positively correlated to the cultural dimensions of uncertainty avoidance, collectivistic, and long-term orientation. Demography variables such as age, gender, education level, and disaster experiences have no relation to the risk perception of climate change. The result enriches the contribution of cultural dimensions in shaping the risk perception of climate change, and the description of Indonesia's cultural dimensions and risk perception of climate change.
\end{abstract}

Key Words: Risk Perception, Climate Change, Uncertainty Avoidance, Collectivistic, and Long-term Orientation

\section{INTRODUCTION}

$\mathrm{R}$ isk perception is an individual evaluation of the possibility of hazard's negative consequences to affect personal life. There are many factors to cause the risk perception to occur and explaining only one factor is never enough. For instance, Knuth, Kehl, Hulse, \& Schmidt(2014), found that the ability to perceive the risk of particular disaster is correlated to the experience of similar disaster previously, the risk perception of a flood would be triggered by the flood experience in the past precisely. There is a limitation of crossover effect of disasters; previous experience of the flood does not necessarily lead to the perceived risk of fire in the future due to the different context of the emergency. Hence, explaining risk perception of hazards as consequence of previous experience is not enough.

In this study, researcher would like to examine cultural dimensions by Hofstede (1984) to influence risk perception especially the risk of climate change. Apart from political and economic situation, cultural value is an interesting variable to investigate. The cultural aspect of human life is already believed to determine the way people interpret risk (Oltedal et al., 2004). Not many research provide plenty explanation about risk perception of climate change and its correlation with cultural dimensions. Besides, study of risk perception of climate change in eastern world countries such as Asia is still limited thus perspective of climate change is dominated by western world countries (US, UK, and Europe). This research will discuss cultural dimensions in Indonesia and its correlation to the risk perception of climate change in this country. It provides another perspective of study in risk perception of climate change and the application of cultural dimensions in particular country, Indonesia.

The cultural dimensions of this study are uncertainty avoidance, collectivism, and long-term orientation (Hofstede, 2011). Those three cultural dimensions are chosen as the construct's items are self-assessment questions while the three others; power distance, masculinity versus femininity, and indulgent versus restraint dimensions are more likely observing the social situations. For example, power distance would ask about how people see the government or leader in a company, whether or not the power is hierarchical is very difficult to judge as everyone has a different level of knowledge and experience. In addition, masculinity versus femininity dimension is not about personal characteristics rather a distribution of value in society such as how male or female should act or take a role, and indulgence versus restrain dimension measures the safety rate in a country, number of obesity and sexual norms (Hofstede, 2011) which also not possible to be generated individually. Therefore, those three dimensions are not applicable to this research because it would be difficult for respondents to make adjudication without enough knowledge or data.

On the other hand, in terms of face validity, uncertainty avoidance, collectivistic, and long-term orientation are more relevant to the study of risk perception of climate change. It is because these three cultural dimensions items could reveal the psychological constructs which related to the preparedness towards disasters such as climate change. Uncertainty avoidance, collectivism, and long-term orientation are easily measured in individual level as its items asking personal 
preferences, for instance how tolerant people to uncertainty situations (uncertainty avoidance), whether or not individual values his/her group more than himself/herself (collectivistic), and whether or not someone has a long-term plans, sacrifices his/her fun today for success in the future (long-term orientation) (Yoo et al., 2011).

In this study, the risk perception and adaptation towards climate change is analyzed by conducting survey in Indonesia. Indonesia is a member of the G-20, and the largest economy in Southeast Asia with the fourth largest population (approximately 270 million) in the world(The World Bank, 2020). It is considerably important to investigate climate change awareness in Indonesia, as it is one ofthe most economically influential countries in the world and has massive development programs in many sectors, including in the industrial sector. Further, Indonesia can be viewed as representative of the Southeast Asian region's socio-cultural situations in order to understand the impact of cultural values on risk perception regarding climate change in the eastern world. It is assumed that different levels of climate change awareness, risk perception, and precaution plans to face the hazards of climate change are determined by the cultural values of the society.

Regarding world economic challenges nowadays, every nation competes in many aspects to ensure they are not left behind. Unfortunately, the way people prosper economy should sacrifice environmental stability. Climate change has become a serious problem today. Some countries perceived the climate change as a serious threat but some other countries even do not believe in climate change. Many people are seemingly still skeptical about its risk. The slow impact of climate change might be one reason for people being skeptical and not prioritizing it as high as other issues, such as terrorist attacks. It seems that people are biased to calculate the objective risk of climate change.

Pertaining to the environmental issue, there is a high demand for Indonesia's palm oil products and others agricultural products leading to massive deforestation, which has been garnering serious attention lately. Indonesia, as an archipelago state, will mostly be victimized by the sea level rising as an effect of climate change. Many research have already been conducted about the geographic impact of climate change on Indonesia. For instance, it is predicted that in 2100, around 1.1 meters of the risen of sea level will make the coastal area and small islands (approximately $90.260 \quad \mathrm{~km}^{2}$ of land) disappear(Susand et al., 2008). Other serious issues, such as the sinking of the Java island, has been receiving national attention.

Several socio-economic and education factors have been proved to affect the risk perception regarding climate change in several countries. In this research, the cultural dimensions that is rooted in the daily life culture is assumed to be able to determine how people perceive and react to the risk situation. A research in the field of climate change perspectives and values has found that the egalitarian culture is an indirect predictor of people supporting climate change policy in the US (Leiserowitz, 2006). Gallup World Poll conducted a survey in 2007-2008 to explore climate change awareness and risk perception of it harming personal and family life in 119 countries (Lee et al., 2015).

The results of Gallup World Poll are displayed in Table 1 below, with only 20 representations of G-20 countries were chosen. Those are the most leading economic countries in the world which comprised of 19 individual countries plus European Union (represented by Netherlands). These countries are not just being chosen based on their economic power but also its representation of continents in the world, and western and eastern world's cultural variety. In addition, the researcher also incorporated the table with the index scores of the cultural dimensions of uncertainty avoidance, individualism, and long-term orientation from the official Geert Hofstede website, which first conducted the survey in 1984 (https://www.hofstede-insights.com/product/comparecountries/).

\begin{tabular}{|c|c|c|c|c|c|c|}
\hline \multicolumn{7}{|c|}{ Table 1. Risk Perception of Climate Change (2007-2008) and Percentage of Cultural Dimensions } \\
\hline No. & Countries & $\begin{array}{c}\text { Climate Change } \\
\text { Awareness (\%) }\end{array}$ & $\begin{array}{c}\text { Climate Change Risk } \\
\text { Perception of the aware } \\
\text { Population (\%) }\end{array}$ & $\begin{array}{c}\text { Uncertainty } \\
\text { Avoidance }\end{array}$ & Individualism & $\begin{array}{c}\text { Long- } \\
\text { Term } \\
\text { Orientation }\end{array}$ \\
\hline 1 & $\begin{array}{c}\text { United } \\
\text { States }\end{array}$ & $>75$ & $50-69$ & 46 & 91 & 26 \\
\hline 2 & Canada & $>75$ & $70-79$ & 48 & 80 & 36 \\
\hline 3 & Mexico & $50-75$ & $>90$ & 82 & 30 & 24 \\
\hline 4 & $\begin{array}{c}\text { United } \\
\text { Kingdom }\end{array}$ & $>75$ & $70-79$ & 35 & 89 & 51 \\
\hline 5 & Russia & $>75$ & $<50$ & 95 & 39 & 81 \\
\hline 6 & Netherlands & $>75$ & $50-69$ & 53 & 80 & 67 \\
\hline 7 & France & $>75$ & $80-89$ & 86 & 71 & 63 \\
\hline 8 & Germany & $>75$ & $50-69$ & 65 & 67 & 83 \\
\hline 9 & China & $50-75$ & $<50$ & 30 & 20 & 87 \\
\hline
\end{tabular}




\begin{tabular}{|c|c|c|c|c|c|c|}
\hline 10 & South Korea & $>75$ & $>90$ & 85 & 18 & 100 \\
\hline 11 & Japan & $>75$ & $>90$ & 92 & 46 & 88 \\
\hline 12 & Indonesia & $30-39$ & $80-89$ & 48 & 14 & 62 \\
\hline 13 & Australia & $>75$ & $70-79$ & 90 & 51 & 21 \\
\hline 14 & South Africa & $30-39$ & $50-69$ & 49 & 65 & 34 \\
\hline 15 & India & $30-39$ & $80-89$ & 40 & 48 & 51 \\
\hline 16 & Saudi & $40-49$ & $80-89$ & 80 & 25 & 36 \\
\hline 17 & Arabia & $>75$ & $>90$ & 75 & 76 & 61 \\
\hline 18 & Braly & $>75$ & $>90$ & 76 & 38 & 44 \\
\hline 19 & Turkey & $50-75$ & $80-89$ & 85 & 37 & 46 \\
\hline 20 & Argentina & $>75$ & $>90$ & 86 & 46 & 20 \\
\hline
\end{tabular}

The score of cultural dimension index is a collective score of a whole nation which not necessarily applicable to a personal or individual level. As the results are the collective score of society, particular persons might act or think differently. That previous surveys (Table 1) indicated that there is a relationship between the cultural dimensions of a country and perception of risk towards climate change. The western countries (North and South America, Europe and Australia) in the survey were mostly aware of the climate change issues (more than $75 \%$ of the population) but very few of them perceived the risk it harming them and their families. Only $80-89 \%$ of the population of France, the leading country of World Climate Change Summit (COP21) in 2015, was aware of the threat of climate change. US, Canada, United Kingdom, Russia, Netherlands, and Germany only had 50$69 \%$ awareness and appraisal of the seriousness of the issue among the population.

After seeing the countries' percentages of risk perception, it is important to discuss the cultural dimensions index more specifically. From the table we can see that most countries with higher long-term orientation score also scored higher in risk perception. For instance, Italy, Netherlands, France, Germany, South Korea, Indonesia, and Japan had more than 60 index score of long-term oriented people and more than $50 \%$ of the population perceived the risk of climate change.50-69\% of the population in Netherlands and Germany perceived the risk, and the other high uncertainty avoidance countries perceived the risk of climate change above $80 \%$. Besides, some countries with high uncertainty avoidance index(above 60), such as Argentina, Italy, Brazil, Turkey, Mexico, France, Germany, South Korea, Japan, Australia, and Saudi Arabia, had more than $80 \%$ of aware population who perceived the risk of climate change. Lastly, more than $80 \%$ of risk perception comes from countries that scored below 50 on individualism index(collectivistic),namely Argentina (46), Brazil (38), India (48), Turkey (37), Mexico $(30 \%)$, South Korea (18\%), Japan (46\%), Indonesia (14\%), Egypt, and Saudi Arabia (25\%). Interestingly, China and Russia also scored higher in long-term orientation but less than $50 \%$ of the population was worried about the risk of climate change and therefore we need to identify more.

A 2011 survey by Natural Climate Change showed that flooding in the United Kingdom had a significant correlation with the perception of climate change and indirect effect on behavioral intentions (Spence et al., 2011). There is not sufficient information in the context of Indonesia on matters such as whether the people's perception of regular flooding in big cities is correlated to climate change. In addition, despite the fact that forest fires have been classified as emergency situations that cause health problems every year and contribute to $10 \%$ of average annual emissions, palm farmers are still burning forests in some parts of Indonesia, especially in Sumatera Island (Foley, 2017).

The experience of disasters supposedly changes people's perspectives and behaviors towards environmental sustainability. There is an expectation that people around the world will take action as soon as possible to address the climate change issue, especially in countries where it is most catastrophic. Efforts towards climate change mitigation, which is triggered by sense of susceptibility and severity of the issue, can be seen in people reducing their energy consumption despite not having encountered the severity directly. On the other hand, individual adaptation, such as switching off lights or driving less, is motivated by awareness and concern regarding climate change, which can be obtained with sufficient information about its impact (Semenza et al., 2011). These risk perceptions, mitigations, and adaptation intentions will also be examined in this study.

\section{Risk Perception}

Risk perception manifests in the perception of threat, which includes perception of efficacy. There are many factors that affect the perception of risk, such as the source of the risk, familiarity of people towards the risk, and frequency of an event occurring(Oltedal et al., 2004). Perception of efficacy is more likely to bring about protective motivations (acceptance), while perception of threat leads to rejection or defensive motivations(Gore \& Bracken, 2005). 
The more people are susceptible to hazards, the more they perceive threat and risk. The way the climate change issue is communicated leads to different interpretations by nations. The tendency to accept or reject the risk messages can be mediated by cultural or adopted values of people. American citizens, in general, perceive climate change as a moderate risk due to climate change concerns being a worldwide issue and not at a local level, and it is also imagined as ice caps melting and being of a non-human nature (Leiserowitz, 2006). Some countries perceive climate change as different conditions, such as high temperatures, melting icebergs, raised sea levels, extinction of some animals, contagious diseases, etc. The climate change orientation is not necessarily something close or something that has rapid effects and direct impacts on small communities or at a personal level. Thus, a majority of citizens perceive the risk of climate change as less serious.

Inouye (2014) explains that risk perception is affected by different levels of social factors. First, safety culture and leadership (macro-level factors) creates regulations and commitment to safety in communities or organizations, and thus, the members of a community have the same level of risk and perception of safety. Second, meso-level factors that are influenced by community or peer pressure to act safely. Despite understanding the risk of unsafe behavior, a person might still do dangerous things owing to conformity. Lastly, the micro-level factor is risk perception being affected by personal knowledge. The more someone's information extends, the more they tolerate risk and remain optimistically biased with regard to believing that negative events are less likely to happen. It leads people to underestimate the vulnerability and severity of an event because they think they control the situation. In particular, risk perception is strongly constructed by the adverse experiences of disasters while people do not really believe it is related to climate change (Frondel et al., 2017). Therefore, it is very important to communicate the ultimate risks of several damages pertaining to climate change.

In the risk communication study, for example, the increasing perception of risk and self-efficacy triggers people to seek more information about the risk to prevent negative effects of hazards (Kievik \& Gutteling, 2011). With risk communication, it is important to motivate people to do something by helping them increase their self-efficacy. Inducing self-efficacy or the belief to be able to do something is likely to increase the followers' inclination to take action as a precaution for climate change. Effective risk communication is motivating people by involving them in a promoted issue, explaining how it is relevant and how it will affect them personally (Gass \& Seiter, 2014). By doing so, the listener will think about messages and consider changing their attitudes for a long time.

To effectively communicate the risk of climate change, authorities should take part in persuading the society to take preventive action as soon as possible. Research in the risk communication field previously explained the correlation of trust to risk perception as both explained probability (Das \& Teng, 2004). Trust has been found to be a construct of selfefficacy and institutional trust, which refers to trust in the capability of people to avoid risk. Hence, the more we trust, the more we feel that our information about the risk is sufficient followed by fewer negative emotions toward risks (ter Huurne \& Gutteling, 2009). When people trust, the level of risk or risk perception becomes low (Das \& Teng, 2004). This clearly implies that trust triggers the confidence level of the addressed party to handle a problem and tackle a hazardous situation.

\section{Cultural Dimensions}

There are six cultural dimensions that have been introduced by Geert Hofstede, small versus large power distance, weak versus strong uncertainty avoidance, individualism versus collectivism, femininity versus masculinity, short-term versus long-term orientation, and indulgence versus restrain. These cultural dimensions are mostly applied in the context of organization and management. Not all dimensions are suitable for this research, and the researcher decided to select the three most influential dimensions, namely weak versus strong uncertainty avoidance, individualism versus collectivism, and short-term versus long-term orientation. Those cultural dimensions are very close to research conducted by Oltedal, Moen, Klempe, and Rundmo(2004)which stated that cultural adherence (hierarchical, individualistic, egalitarian and fatalistic) is the best predictor of risk perception, particularly in the case of environmental sustainability. Hierarchical, individualistic, egalitarian and fatalistic are the cultural values that Oltedal, Moen, Klempe, and Rundmo explained to have influenced the way people perceive risk. According to that finding, researcher ellaborated the proximity of that four cultural values explained by Oltedal, Moen, Klempe, and Rundmo with cultural dimensions by Hofstede and found that hierarchical culture is identical with the dimension of uncertainty avoidance, individualistic culture is the same as individualistic vs collectivistic dimension and fatalistic culture is the opposite of long-term orientation dimension.

There are four cultural values in previous research conducted by Oltedal, Moen, Klempe, and Rundmo (2004),hierarchical, individualistic, egalitarian, and fatalistic, which are influential to building risk perception. Hierarchical culture is the culture where people respect authority, follow law and order, and accurately place the ethical standards of societal right and wrong(Oltedal et al., 2004). Hierarchical culture suits to highpower distance and uncertainty avoidance characteristics of Hofstede's cultural dimensions. Both power distance and uncertainty avoidance are sufficiently represented in the hierarchical culture characteristics. In this research, uncertainty avoidance is a dimension where people are uncomfortable with uncertainty and try to tackle unpredictable conditions with strict regulation, following absolute truth, and having zero tolerance towards deviant opinions (Hofstede, 2011). People in hierarchical cultures believe that nature has 
limits in order to preserve itself, and thus humans should not exploit nature beyond nature's ability to repair the damage. While perceiving risk, as long as the risk is justified by experts or authorities, people in this culture will accept the risk (Oltedal et al., 2004).

Individualistic, as opposedto collectivistic culture, exalts freedom more; and hence, people in this culture will accept risk if it does not limit people's freedom. In contrast, the collectivistic culture integrates individuals with their group and there is exchange ofloyalty among the members (Hofstede, 2011). Individualistic culture does not particularlycare about how people treat nature owing to the belief that nature is self-preserving and will be able to regain homeostasis(Oltedal et al., 2004).

Fatalistic cultures stand in opposition to the cultural dimension of long-term orientation. Long-term orientation encourages people to always have a precaution plan while fatalistic cultures just face problems without preparation as they believe in fate.Fatalistic cultures perceive risk indifferently and prefer to not worry about unavoidable hazards due to the belief that peopledo not have the ability to tackle the risk. Nature has never clearly reacted to people, and therefore, people in fatalistic cultures do not make any judgment of whether exploitation of nature is right or wrong (Oltedal et al., 2004).

Indonesia is positioned at high collectivism, moderate longterm orientation and moderate uncertainty avoidance level, as depicted by indices of 14 (individualistic index),62 and 48 respectively(Hofstede, 1984). Climate change is still believed as being uncertain for many people and the weak and strong dimension of uncertainty avoidance would have an impact on different levels of societal comfort towards the ambiguity of climate change. Table 1 shows some countries that scored highly on uncertainty avoidance also do so on risk perception of climate change, such as France, South Korea, Japan, and Australia (Hofstede Insight, 2017).Furthermore, the consequences of climate change is gradual damage to the environment and needs preparatory or precautionary actions to be take. Thus, long-term versus short-term orientation distinguishes people's reactions and preparation with regard to facing this issue. Lastly, individualism versus collectivism has been included due to climate change adaptation, and mitigation should not only be seen as large societal actions but also personal actions such as energy saving.

Uncertainty Avoidance is the degree of tolerance for new or different situations, which are uncommon or unstructured. When this cultural dimension is high, people believe in absolute truth and reduce possibilities of being in uncertain situations, such as with very tight regulation (Hofstede \& Mccrae, 2004). There is an emotional need for formalization of structure, standardization of procedure, and ritualization of behavior (Hofstede, 1984). There is a strong emotional need for rules and belief religion, philosophy, and science as ultimate truths (Hofstede, 2011). In terms of strategic planning, cultures with less uncertainty avoidance have better fundamental goals and organization activities but do not necessarily adapt to environmental changes effectively.

Collectivism manifests through the integration of people intoa group, such as extended families, clans, tribes, etc. (Hofstede, 1984, 2011). People are motivated by group interests, and thus consider placing personal goals as the highest goals as inappropriate. It is also considered acceptable to be dependent on relatives, as income is usually shared(Hofstede, 1984). On the other hand, individualist cultures consider every person as independent and as individuals instead of as in-group or outgroup members. People within individualism are open and direct in terms of communication and speaking their minds, while people in collectivism always keep harmony as relationships are very important (Hofstede, 2011). In a collectivistic culture, there is an expectation that every individual conform to the ideals of the society (Hofstede Insight, 2017).

Lastly, Long-term orientation is a situation where people perceive important events in life as occurring in the future and not just now or in the past (Hofstede, 2011). The perception involves the importance planning for the future and how far the preparation of the future vision extends, instead of focus on the quality of the plan (Mai, 2015). This culture perceives success as a result of hard work and sets their important goals to be thrift and persevering(Hofstede, 2011).A high score in long-term orientation also implies that the society is capable of change conditions by adapting to traditions and believing that the truth depends on the context, time, and situation (Hofstede Insight, 2017).

Cultural value is one of the strongest antecedents of human behavior, including the way people perceive risk (Oltedal et al., 2004). Risk perception of climate change is the initial factor that triggers mitigation of climate change, which is a pivotal aspect of reducing the dangers of climate change in the future by taking precautionary actions from now. This research aims to answer whether the three cultural dimensions identified by Hofstede (uncertainty avoidance, collectivistic, and long-term orientation) affect risk perception towards climate change in Indonesia. The hypothesis is as follows: Cultural dimensions of uncertainty avoidance, collectivism, and long-term orientation are positively correlated to risk perception and adaptation of climate change.

\section{METHOD}

This research is conducted in Indonesia owingto the sociocultural conditions and disaster experiences of the people. This study focuses on cities that have been damaged by flooding and forest fires. The cities have been chosen in order to observe variation of cultural background, demography, and catastrophes to affect the risk perception regarding climate change. This study used online survey forms. Data collection regarding risk perception and adaptation to climate change and cultural dimensions was done using online survey form in Qualtrics. The online survey was distributed to participants in 
the duration of three weeks by way of the researcher visiting universities and organizations in several big provinces in Indonesia, such as the capital city Jakarta, Riau (Sumatera), South Sulawesi, West Sulawesi, West Java, East Java, and Jogjakarta. Besides, the survey also undergoes promotion through the researcher asked participants to voluntarily share the survey link to their social media platforms like Facebook, Whatsapp, and Line to reach more respondents from other provinces. Sharing information through internet or social media is very promising in Indonesia as 96 million of population are actively using social media and become fourth largest population using social media in the world after China, India and USA (Katadata Indonesia, 2017).

\section{Measurement Instruments}

The risk perception of climate change survey form was adapted from Semenza, Ploubidis, and George (2011). It enquires about extent to which people perceive the severity, susceptibility, self-efficacy, mitigation, and adaptation of climate change. Hofstede's Cultural Dimensions (uncertainty avoidance, collectivism, and long-term orientation) was used with the survey questions developed by Yoo, Donthu, and Lenartowicz, (2011). The survey was administered in Bahasa Indonesia and used 5-point Likert Scale.

The survey questions about cultural dimensions consisted of 17 items divided into 5 items regarding uncertainty avoidance, 6 items regarding collectivism, and 6 items regarding longterm orientation. Uncertainty avoidance examines how important it is to follow rules in daily activities, such as following instruction and procedures at work; how important it is for the rules to be spelled out; etc. the collectivism variable was measured by asking respondents how they posited themselves in the society. The general questions were whether they considered their identity more as an independent person or part of their larger group, or to what extent they consider their acts will affect their group. For long-term orientation, questions revolved around how respondents perceived the necessity of a future. These questions were related to planning, persistence, and working hard for a better future. Besides, risk perception and adaptation to climate change are compiled from several aspects, such as perceived susceptibility, perceived severity, perceived benefits, and perceived barriers, cues of action, self-efficacy, mitigation, emergency plan, and emergency kit. These aspects are represented as a 9-itemquestionnaire. For instance, one of the items is "I believe climate change could affect my way of life or lifestyle if I do not prepare adequately". Details of cultural dimensions, risk perception, and adaptation of climate change arein the appendix.

Previously, survey questions regarding risk perception of climate change were never administered in the Indonesian language and were conducted as yes or no answer questions. The researcher decided to modify the questions into Bahasa Indonesia and the "yes-no" response to a5-point Likert Scale to measure the degree of concession towards climate change conscientiously. From Table 2, Cronbach's Alpha analysis for risk perception and adaptation inventory shows $71 \%$ reliability score for measurement of risk perception after survey-format modification, which means that it is a compatible tool to measure risk perception of climate change in Indonesia. Moreover, the cultural dimension depicts no lower than $60 \%$ reliability score, consists of $75 \%$ the uncertainty avoidance, and $80 \%$ and $66 \%$ of collectivism and long-term orientation respectively.

Table 2: Descriptive Statistics and Reliability Dependent and Independent Variables

\begin{tabular}{|c|c|c|c|c|}
\hline & $\mathrm{M}$ & $\mathrm{SD}$ & $\begin{array}{c}\text { Cronbac } \\
\text { h's } \\
\text { Alpha }\end{array}$ & Example of Items \\
\hline $\begin{array}{c}\text { Uncertainty } \\
\text { Avoidance }\end{array}$ & 4.724 & 2.221 & 0.751 & $\begin{array}{c}\text { Rules and regulations are } \\
\text { important because they } \\
\text { inform me about what is } \\
\text { expected of me }\end{array}$ \\
\hline $\begin{array}{c}\text { Collectivis } \\
\text { m }\end{array}$ & 3.340 & 5.135 & 0.807 & $\begin{array}{c}\text { Individuals should sacrifice } \\
\text { their self-interest for the } \\
\text { group }\end{array}$ \\
\hline $\begin{array}{c}\text { Long-Term } \\
\text { Orientation }\end{array}$ & 4.478 & 3.056 & 0.665 & $\begin{array}{c}\text { Giving up today's fun for } \\
\text { future success }\end{array}$ \\
\hline $\begin{array}{c}\text { Risk } \\
\text { Perception }\end{array}$ & 3.676 & 6.225 & 0.717 & $\begin{array}{c}\text { I believe that climate change } \\
\text { can endanger my life }\end{array}$ \\
\hline
\end{tabular}

\section{Sample Characteristics}

705 participants recorded on Qualtrics report but only 562 respondents completely participated in the survey, which covers almost 34 provinces in Indonesia. 143 participants/records were not included to the analysis because they aborted their participation before completing all questions. Majority of the respondents hail from Sulawesi (Celebes), Java, and Sumatera islands as the researcher visited these places and socialized the survey form directly. In addition, there are some respondents from other islands such as Bali and Nusa Tenggara islands, Maluku (Moluccas), Kalimantan (Borneo), and Papua who also participated after the survey form was promoted via social media. From Table 3 , we can see respondents are between the age range of 15-58 years old and the educational level ranged from junior high school to university level. In terms of experience of disasters (floods and forest fires), the respondents represented both experienced and inexperienced people in this survey.

\begin{tabular}{|c|c|c|}
\hline \multicolumn{3}{|c|}{ Table3. Socio-Demographic Profile } \\
\hline $\begin{array}{c}\text { Socio-demographics } \\
\text { variables }\end{array}$ & Frequency & Percentage \\
\hline Gender & & \\
\hline Male & 240 & 43 \\
\hline Female & 321 & 57 \\
\hline Others & 1 & 0 \\
\hline Age & & \\
\hline $15-25$ & 344 & 61 \\
\hline $26-35$ & 175 & 31 \\
\hline
\end{tabular}




\begin{tabular}{|c|c|c|}
\hline $36-45$ & 37 & 7 \\
\hline $46-58$ & 6 & 1 \\
\hline Education Level & & \\
\hline Elementary School & 0 & 0 \\
\hline Junior High School & 5 & 1 \\
\hline Senior High School & 106 & 19 \\
\hline University & 451 & 80 \\
\hline Disaster Experience & & \\
\hline Not Experienced & 257 & 46 \\
\hline Experienced & 305 & 54 \\
\hline
\end{tabular}

The respondents ages ranged between 15 to 58 years old $(M=$ 26, $N=562$ ). Most respondents were in the early adulthood stage, $61 \%$ were between the age range of $15-25$, and $31 \%$ between the age ranges of $26-35$ years old. According to latest national census in Indonesia (2010), $63.55 \%$ of Indonesian population is in productive age, from 15 to 59 years old. Almost 30 million (8.79\%) of Indonesian population comes from age range 15-19 years old, $8.37 \%$ from age range $20-24$ years old, $8.97 \%$ from age range $25-29$ years old and $8.34 \%$ from age range 30-34 years old (Badan Pusat Statistik, 2017b).Around $41 \%$ of respondents in this survey are from Java Island which also well-known as the most congest area in Indonesia by more than $1000 \mathrm{~km}^{2}$ followed by Sulawesi Island 32\% respondents with congestion 100-499 $\mathrm{km}^{2}$ (BPS-Statistics Indonesia, 2017). This can be seen as representation of Indonesian population in terms of age range and population distributions geographically.

More than half $(57 \%)$ of the respondents were female while $43 \%$ is male respondents. A vast majority of the respondents were highly educated, as $80 \%(n=451)$ of them had graduated from university or were undergoing their studies at different level ata university. Furthermore, most importantly, it can be seen that more than $50 \%$ respondents had experienced disaster, floods or forest fires. In terms of educational background, national census in Indonesia indicated that more than $30 \%$ of Indonesian population above 15 years old were graduated from senior high school or university level while $54.36 \%$ populations just finished their primary and junior high school(Badan Pusat Statistik, 2017a). From the census data, it seems that the education level was not properly represented in this study.

Nevertheless, this research is identifying how cultural dimensions could increase or decrease risk perception of climate change hence decided to use this representative sample is according to how intense the respondents connected to the society and adopted the cultural dimensions. In addition, risk perception is not significantly related to education level as found by Pádua, Santos, \& Horta (2013) in their research about risk perception of diabetes. Risk perception of the environment, for instance, can also be significantly triggered by education if the higher education or department/majors were related to environmental studies(Eren Durmuş-Özdemir \& Sevinç Şener, 2016). Therefore, the sample in this research is representative in terms of cultural background, age distribution and geographic distribution of the population.

\section{RESULTS}

The first step to analyze the data is conducting hierarchical multiple regression analysis to test how the demography variable (age, education level, gender and disaster experience) affects the dependent variable (risk perception of climate change). The analysis model (Table 4) shows no significant change of risk perception and adaptation by controlling the demography variable $\left(R^{2}=0.001, p=0.957\right)$, meaning that there is no contribution of the demography variable to the rise of risk perception of climate change.

\begin{tabular}{|c|c|c|c|c|c|}
\hline \multicolumn{6}{|c|}{ Variables } \\
\hline Model & Variable Predictors & $\mathrm{R}$ & $\mathrm{R}^{2}$ & $\mathrm{~F}$ & $\mathrm{p}$ \\
\hline I & $\begin{array}{c}\text { Disaster Experience, Age, } \\
\text { Gender, Education }\end{array}$ & $0.034^{\mathrm{a}}$ & 0.001 & 0.163 & 0.957 \\
\hline II & $\begin{array}{c}\text { Disaster Experience, Age, } \\
\text { Gender, Education, Long- } \\
\text { Term Orientation, } \\
\text { Collectivism, Uncertainty } \\
\text { Avoidance }\end{array}$ & $0.447^{b}$ & 0.200 & 19.813 & 0.000 \\
\hline
\end{tabular}

Each demographical variable's contribution can be seen in Table 5, which amplifies that there is no significant correlation between gender $(p=0.749)$, age $(p=0.553)$, education level $(p=0.800)$, and even disaster experience $(p=0.652)$ towards risk perception of climate change. Interestingly, education level and disaster experiences are not significantly correlated to trigger risk perception of climate change in this study. This finding can be explained by the previous study of risk perception by Pádua, Santos, \& Horta, (2013)which found that education level is not a predictor of people perceive the risk especially the risk of health (diabetes) and the higher education should be related to a particular environmental issue (e.g. climate change) to adequately increase the awareness of climate change (Eren DurmuşÖzdemir \& Sevinç Şener, 2016). Another study of disaster's cross-over effects found that significant correlation of experience to cause people perceive the risk of particular disaster can be triggered by the similar disaster previously or at least required similar context of experience. The current survey's results indicating that the appraisal of climate change impact is not manifested in flood or forest fire experiences thus the risk perception of climate change is not related to disaster experience.

There are some domains of risks and one of them is the health risks domain. Although health risks is related to the environmental risks, it has been found that people from different age group have similar risk perception towards environmental risks domain(Bonem et al., 2015).The older people have more concern about the health risks domain than 
younger people but in terms of environmental risks, both older and younger people have no difference of risk perception. This is because age range only makes difference in risk perception if the risk was related to whether or not someone has ability to avoid the risk. Risk of the environment are unable to control while health risks are avoidable(Bonem et al., 2015). Current survey's result also found that there is no correlation of age differences and risk perception of climate change.

In terms of gender, some researches previously have found that female perceived risk higher than male. Morioka(2014), found that fathers in Japan were less concerned about the risk of nuclear radiations towards their family health than the mothers. Mothers in Japan dominated the movement of asking government to reduce the nuclear radiation impact after the explosion of Fukushima Daiichi Nuclear Power Plant. In contrast, there was no significant difference of risk perception of female and male towards social risks domain (risks related to the relationship with others) (Harris et al., 2006) and gender has no significant effect on fear appealing process (Witte \& Allen, 2000).

The different domain of risks has different effect on risk perception of particular group of people. This explains why the demography variables have no significant effect on risk perception of climate change, as risk of climate change is in domain of environmental risks. The result clarifies that the demography variable doesnot confound to the alteration of risk perception to climate change in Indonesia.

On the other hand, Table 5 shows significant contribution of each cultural dimension variable towards the dependent variable, risk perception of climate change. Certainly, uncertainty avoidance $(p=0.002)$, collectivism $(p<0.001)$, and long-term orientation $(p<0.001)$ are good predictors of risk perception of climate change. Long-term orientation has a higher impact on perception of climate change with the coefficient $\mathrm{B}=0.612$ followed by uncertainty avoidance $(B=0.346)$ and collectivism $(B=0.245)$.

\begin{tabular}{|c|l|c|c|c|}
\hline \multicolumn{5}{|c|}{ Table 5. Significant Contribution Each Variables } \\
\hline \multirow{3}{*}{ Model } & Variable Predictors & $\mathrm{B}$ & $\mathrm{T}$ & $\mathrm{p}$ \\
\hline \multirow{10}{*}{1} & (Constant) & 33.481 & 11.815 & 0.000 \\
\cline { 2 - 5 } & Gender & -0.079 & -0.143 & 0.886 \\
\cline { 2 - 5 } & Age & -0.012 & -0.212 & 0.832 \\
\cline { 2 - 5 } & Education & -0.008 & -0.011 & 0.992 \\
\cline { 2 - 5 } & Disaster Experience & 0.126 & 0.230 & 0.818 \\
\hline \multirow{5}{*}{2} & Constant) & 2.168 & 0.548 & 0.584 \\
\cline { 2 - 5 } & Gender & 0.115 & 0.231 & 0.817 \\
\cline { 2 - 5 } & Age & -0.002 & -0.039 & 0.969 \\
\cline { 2 - 5 } & Education & 0.206 & 0.314 & 0.753 \\
\cline { 2 - 5 } & Disaster Experience & 0.277 & 0.564 & 0.573 \\
\cline { 2 - 5 } & Uncertainty & 0.349 & 3.040 & 0.002 \\
\hline
\end{tabular}

\begin{tabular}{|l|l|c|c|c|}
\hline & Collectivism & 0.248 & 5.087 & 0.000 \\
\cline { 2 - 5 } & Long-term Orientation & 0.612 & 7.639 & 0.000 \\
\hline \multicolumn{4}{|c|}{ Dependent Variable: Risk Perception and Adaptation } \\
\hline
\end{tabular}

Furthermore, the research question of this research is whether the three cultural dimensions are positively correlated to the perceived risk of climate change in Indonesia. As clearly depicted by Table 4, $\mathrm{R}$ square dramatically increased after conducting cultural dimensions in hierarchical regression model from $0 \%(R=0.001, F=0.163)$ up to $20 \%(R=0.200$, $F=19.813)$. This indicates that after adding the cultural dimensions to the model, the predictive capacity of the model at predicting overall risk perception increased by approximately $20 \%$. Hierarchical multiple linear regression tested the significance of the model and the result showed the $p$ value $0.000<0.05\left(R^{2}=0.200, F=19.813\right)$ meaning that the higher cultural dimension of uncertainty avoidance, collectivism, and long-term orientation, the higher the people perceived the risk of climate change. It indicates that there is a positive correlation between cultural dimensions and risk perception of climate change in Indonesia. Therefore, the hypothesis of this research is accepted.

\section{DISCUSSION AND CONCLUSION}

There is positive correlation of cultural dimensions of uncertainty avoidance, collectivism, and long-term orientation with the risk perception of climate change in Indonesia $(p<$ 0.001). The result supports the hypothesis of this research about positive correlation of risk perception and cultural dimensions, specifically in Indonesia.

This finding is strengthened by previous findings about risk perception of climate change and the cultural dimensions survey, where risk perception mostly occurred in long-term oriented countries, such as France, South Korea, Japan, and Indonesia (Lee et al., 2015). Moreover, Lee et al. (2015)stated that above $80 \%$ of the populations in Mexico, France, Germany, South Korea, Japan, Australia, Egypt, and Saudi Arabia perceived the risk of climate change and also scored highly in uncertainty avoidance (above 60\%). Mexico, South Korea, Japan, Indonesia, Egypt, and Saudi Arabia are countries with low individualism who perceived climate change as a serious threat.

Although uncertainty avoidance, collectivism, and long-term orientation in Indonesia are highly scored by the survey, the collectivism variable has a lowest contribution to the model ( $B$ $=0.245$ ). This explains why some countries with higher score of long-term orientation and uncertainty avoidance and lower scores in collectivism (individualist) still perceive the risk of climate change as high, for instance Australia, Netherlands, France, and Germany. Nonetheless, the current results indicate that high scores in uncertainty avoidance, collectivism, and long-term orientation positively correlated with higher risk perception of climate change, meaning that the hypothesis of this research is accepted. 
As clearly seen from the 2007-2008 survey, even people aware of the climate change issue do not necessarily increase the level of risk perception and mitigation of climate change. Therefore, deliberating socio-cultural condition is undeniably a pivotal aspect of forming the perception of severity in society. Using cultural values as indicators of risk perception of climate change is also supported by the finding in Latino populations in the US, who believed that climate change is happening and $78 \%$ of them are more worried about the impact of climate change than the American population as a whole (Leiserowitz et al., 2017). Although living in the same country, the Latino-American population is very supportive towards climate change policies as compared to the American.

From Table 2, it is clearly visible that the current level of uncertainty avoidance is pretty high $(M=4.724)$, while scores from the previous survey by Hofstede (1984) in his official website is completely distant. The survey conducted by Hofstede shows 48 of the score index for uncertainty avoidance while the recent survey found that at least 292 (52\%) respondents agreed to the favorable items of the uncertainty avoidance survey. There must have been substantial changes in the years in between, thus resulting inthe different scores of uncertainty avoidance in Indonesia.

More than half the respondents agreed to the uncertainty avoidance items, meaning that the score of uncertainty avoidance is actually higher in Indonesia recently. Considering the mean of both collectivism and long-term orientation, it was scored higher as compared to previous and recent surveys that consistently describe the actual scores of both cultural dimensions. Generally, the score of three cultural dimensions; uncertainty avoidance, collectivism, and longterm orientation from this research are interpreted as high.

Risk perception of climate change on the previous survey (2007-2008) is pretty much related to question number one and two of the current survey: "I believe climate change could affect my way of life or lifestyle if I do not prepare" and "I believe that climate change can endanger my life". The score of both the first and second questions indicate that most respondents in this survey agree to the risk of climate change. For instance, the question about perceived severity, approximately $45 \%$ of respondents in Indonesia answered that they are agree to the severity of climate change and around $20 \%$ respondedthat they somewhat agree. The result fortifies the fact that the risk of climate change is known by more than half of respondents, about $65 \%$ in the current survey as also depicted by previous survey in 2007-2008, around 80-89\% of Indonesian respondents. Recently, the result confirms that the risk perception of climate change in Indonesia are still high, above $60 \%$ of total respondents.

According to Hofstede (2011), high uncertainty avoidance is the condition where society tries to control a future that cannot be predicted. The consequence of the high uncertainty avoidance is that people tend to prevent the negative consequences of behavior by ruling strictly towards their deeds. The higher score of the uncertainty avoidance also triggered one country to design a great plan and structure fortheir nation to face the threat(Hofstede, 2011). In terms of precautions for climate change, the issue has been made very clear by media reports and research publications, and therefore, society is likely to consider it as a serious problem that needs extra attention. Society with high uncertainty avoidance strongly believed truth in science, the scientific report of climate change around the world could be the powerful trigger that leads to very futuristic plans and regulations being put in place to prevent the consequences of climate change.

In terms of long-term orientation, societies with high scores in this dimension will carefully plan the future and should be able to adapt to particular contexts or situations (Hofstede, 2011). Climate change is a real threat of the earth temperature rising in the long-term, and hence, after accepting the issue as serious, the society must take preventive action as their adaptation to a new circumstance. Another strong point of long-term orientation is thrift and perseverance (Hofstede, 2011). Thrift and perseverance could trigger the society to be committed to the energy saving program and reduce the pollution, for example.

Furthermore, the collectivism culture is the culture where people consider the society for their actions and thoughts and where members of group or society are highly interdependent each other(Hofstede Insight, 2017). People with high collectivism also try to protect the member of their group and receive respect and loyalty from the members as exchange. When the common goal is to tackle climate change problems, all members of the group or the collectivistic society will regard it as their concern. In the situation where people appraise climate change as a serious societal problem, collectivistic society will carefully consider their actions as not harming their group by violating the common rules. They care about future generations and the people who will be victimized by their deeds, and thus, tend not to be egoistic and act according to personal preferences as lone individuals. Therefore, being situated in a collectivistic culture could result in supportive actions related to the group's well-being.

As a developing country, Indonesia is facing serious issues regarding climate change due to the deforestation and increasing emission of carbon from the large population. Fortunately, Indonesia is adequately aware of the risk of climate change and has tried to adapt its behavior, with $67 \%$ of respondents both slightly agreeing and agreeing about the severity of the issue. The result of the survey profoundly proves that the socio-cultural aspect is also related to the degree of risk perception and adaptation towards climate change, not only the politic and economic situations. The cultural dimension of uncertainty avoidance, collectivism, and long-term orientation should be scored highly to infer that the society perceives the risk of climate change as a serious threat and is willing to adapt itsbehavior. Indonesia represents the high score of uncertainty avoidance, collectivism, and long- 
term orientation as majority Asian countries have. This research results seemingly explain that the possibility of other countries which have characteristics like Indonesia might be facing a similar situation. Furthermore, these findings can help better risk communication program by considering the cultural dimensions of the target society.

\section{REFERENCES}

[1] Badan Pusat Statistik. (2017a). Population 15 Years of Age and Over by Educational Attainment and Last Week Activity. Www.Bps.Go.Id.

http://sp2010.bps.go.id/index.php/site/tabel?search-

tabel=Penduduk+Berumur+15+Tahun+Keatas+Menurut+Pendidik an+Tertinggi+yang+Ditamatkan+dan+Kegiatan+Seminggu+yang+ Lalu\&tid=332\&search -

wilayah=Indonesia\&wid=0000000000\&lang=id

[2] Badan Pusat Statistik. (2017b). Population by Age Group and Sex. Www.Bps.Go.Id.

http://sp2010.bps.go.id/index.php/site/tabel?search-

tabel=Penduduk+Menurut+Kelompok+Umur+dan+Jenis+Kelamin $\&$ tid $=336 \&$ search -

wilayah $=$ Indonesia $\&$ wid $=0000000000 \&$ lang $=$ id

[3] Bonem, E. M., Ellsworth, P. C., \& Gonzalez, R. (2015). Age Differences in Risk: Perceptions, Intentions and Domains. Journal of Behavioral Decision Making, 28(4), 317-330. https://doi.org/10.1002/bdm.1848

[4] BPS-Statistics Indonesia. (2017). STATISTCAL Yearbook of INDONESIA 2017.

[5] Das, T. K., \& Teng, B. S. (2004). The risk-based view of trust: A conceptual framework. Journal of Business and Psychology, 19(1), 85-116. https://doi.org/10.1023/B:JOBU.0000040274.23551.1b

[6] Eren Durmuş-Özdemir, \& Sevinç Şener. (2016). The Impact of Higher Education on Environmental Risk Perceptions. China-USA Business Review, 15(9). https://doi.org/10.17265/15371514/2016.09.005

[7] Foley, R. (2017). Wet and Wild: Indonesian Forest Fires. Center for International Forestry Research (CIFOR). http://blog.cifor.org/49656/wet-and-wild-indonesian-forestfires?fnl=en

[8] Frondel, M., Simora, M., \& Sommer, S. (2017). Risk Perception of Climate Change: Empirical Evidence for Germany. Ecological Economics, 137, 173-183. https://doi.org/10.1016/j.ecolecon.2017.02.019

[9] Gass, R. H., \& Seiter, J. S. (2014). Pearson new international edition: Persuasion, social influence and compliance gaining. Pearson.

[10] Gore, T. D., \& Bracken, C. C. (2005). Testing the Theoretical Design of a Health Risk Message: Reexamining the Major Tenets of the Extended Parallel Process Model. Health Education and Behaviour, 32 (1)(Ohio), 27-41. https://doi.org/DOI: 10.1177/1090198104266901

[11] Harris, C. R., Jenkins, M., \& Glaser, D. (2006). Gender Differences in Risk Assessment: Why do Women Take Fewer Risks than Men? Judgment and Decision Making, 1(1), 48-63.

[12] Hofstede, G. (1984). Cultural Dimensions In Management And Planning. Asia Pacific Journal of Management, January, 81-99.

[13] Hofstede, G. (2011). Dimensionalizing Cultures: The Hofstede Model in Context Dimensionalizing Cultures: The Hofstede Model in Context. 2, 1-26.

[14] Hofstede, G., \& Mccrae, R. R. (2004). Personality and Culture Revisited : Linking Traits. Cross-Cultural Research, 38(1), 52-88. https://doi.org/10.1177/1069397103259443

[15] Hofstede Insight. (2017). Compare Countries. Www.HofstedeInsights.Com. insights.com/product/compare-countries/

[16] Inouye, J. (2014). Risk perception: Theories, strategies, and next steps (0814 900004811). 1-11. http://www.nsc.org/CambpellInstituteandAwardDocuments/WP-
Risk Perception.pdf

[17] Katadata Indonesia. (2017). 2022, Pengguna Media Sosial Indonesia Mencapai 125 Juta. Databox.Katadata.Co.Id. https://databoks.katadata.co.id/datapublish/2017/08/22/2022pengguna-media-sosial-indonesia-mencapai-125-juta

[18] Kievik, M., \& Gutteling, J. M. (2011). Yes, we can: Motivate Dutch citizens to engage in self-protective behavior with regard to flood risks. Natural Hazards, 59(3), 1475-1490. https://doi.org/10.1007/s11069-011-9845-1

[19] Knuth, D., Kehl, D., Hulse, L., \& Schmidt, S. (2014). Risk Perception, Experience, and Objective Risk: A Cross-National Study with European Emergency Survivors. Risk Analysis, 34(7), 1286-1298. https://doi.org/10.1111/risa.12157

[20] Lee, T. M., Markowitz, E. M., Howe, P. D., Ko, C.-Y., \& Leiserowitz, A. A. (2015). Predictors of public climate change awareness and risk perception around the world. https://doi.org/10.1038/NCLIMATE2728

[21] Leiserowitz, A. (2006). Climate change risk perception and policy preferences: The role of affect, imagery, and values. Climatic Change, 77(1-2), 45-72. https://doi.org/10.1007/s10584-0069059-9

[22] Leiserowitz, A., Rosenthal, S., \& Cutler, M. (2017). Climate Change in The Latino Mind: May 2017. Yale University, New Haven, CT: Yale Program on Climate Change Communication.

[23] Mai, N. P. (2015). Hofstede's five value dimensions of culture (pp. 1-19).

[24] Morioka, R. (2014). Gender difference in the health risk perception of radiation from Fukushima in Japan: The role of hegemonic masculinity. Social Science and Medicine, 107, 105112. https://doi.org/10.1016/j.socscimed.2014.02.014

[25] Oltedal, S., Moen, B.-E., Klempe, H., \& Rundmo, T. (2004). Explaining risk perception: an empirical evaluation of cultural theory. In Risk Decision and Policy (Vol. 85, Issue 2). https://doi.org/10.1080/135753097348447

[26] Pádua, M., Santos, J., \& Horta, H. (2013). Is there a link between education, risk perception, and health outcomes in diabetes in the context of primary intervention among the elderly population? ALTAC Conference Journal, 2013, October. http://www.altec2013.org/programme_pdf/1589.pdf

[27] Semenza, J. C., Ploubidis, G. B., \& George, L. A. (2011). Climate change and climate variability: personal motivation for adaptation and mitigation. Environmental Health. https://doi.org/10.1186/1476-069X-10-46

[28] Spence, A., Poortinga, W., Butler, C., \& Pidgeon, N. F. (2011). Perceptions of climate change and willingness to save energy related to flood experience. Nature Climate Change, 1. https://doi.org/10.1038/NCLIMATE1059

[29] Susand, A., Herlianti, I., Tamamadin, M., \& Nurlela, I. (2008). Dampak Perubahan Iklim TerhadapKetinggian Muka Laut Di Wilayah Banjarmasin. Jurnal Ekonomi Lingkungan, 12(Bandung).

[30] ter Huurne, E. F. J., \& Gutteling, J. M. (2009). How to trust? The importance of self-efficacy and social trust in public responses to industrial risks. Journal of Risk Research, 12(783016864), 809824. https://doi.org/10.1080/13669870902726091

[31] The World Bank. (2020). Having maintained political stability, Indonesia is one of East Asia Pacific's most vibrant democracies, emerging as a confident middle-income country. Www.Theworldbank.Org. https://www.worldbank.org/en/country/indonesia/overview\#3

[32] Witte, K., \& Allen, M. (2000). A meta-analysis of fear appeals: Implications for effective public health caampaigns. Health Education \& Behavior, 27(5), 591-615. https://doi.org/10.1177/109019810002700506

[33] Yoo, B., Donthu, N., \& Lenartowicz, T. (2011). Measuring Hofstede' s Five Dimensions of Cultural Values at the Individual Level: Development and Validation of CVSCALE Measuring Hofstede 's Five Dimensions of Cultural Values at the Individual Level: Development and Validation of. 23, 193-210. https://doi.org/10.1080/08961530.2011.578059 
APPENDIX

\begin{tabular}{|c|c|c|c|c|}
\hline \multicolumn{5}{|c|}{ Appendix 1. Risk Perception Survey Constructs } \\
\hline No. & Construct & Questions & Mean & SD \\
\hline 1 & $\begin{array}{c}\text { Perceived } \\
\text { susceptibility }\end{array}$ & I believe climate change could affect my way of life or lifestyle if I do not prepare \\
appropriately & 4.4 & 0.8 \\
\hline 2 & Perceived severity & I believe that climate change can endanger my life & 3.9 & 1.2 \\
\hline 3 & Perceived benefits & Personal preparation for climate change can save my life & 3.9 & 1.1 \\
\hline 4 & Perceived barriers & There are serious obstacles and barriers to protecting myself from the negative \\
consequences of climate change & 3.6 & 1.1 \\
\hline 5 & Cues to action & I have the necessaryinformation to prepare for the impacts of climate change & 3.4 & 1.3 \\
\hline 6 & Self-efficacy & I have the ability and power to protect myself from the dangerous events that may occur \\
due to climate change & 3.2 & 1.2 \\
\hline 7 & Mitigation & $\begin{array}{c}\text { I have reduced my energy consumption in response to what Ihave heard about global } \\
\text { climate change }\end{array}$ & 3.9 & 1.1 \\
\hline 8 & Emergency plan & $\begin{array}{c}\text { My household currently has a plan for what to do to protect ourselves in the event of a } \\
\text { disaster or emergency.Such a plan includes how I would evacuate my home or how I will } \\
\text { stay in contact with other family members. }\end{array}$ & 3.1 & 1.4 \\
\hline 9 & Emergency kit & $\begin{array}{c}\text { Some households have an emergency kit that includes items such as airst aid kits, } \\
\text { thermometers, flashlights and batteries, food that won't spoil, sufficient drinking water, and } \\
\text { other essentials people need to live for at least three days in the event of a disaster or } \\
\text { emergency. My household also has this kindof emergency kit }\end{array}$ & 3.2 & 1.4 \\
\hline
\end{tabular}

\begin{tabular}{|c|c|c|c|c|}
\hline \multicolumn{5}{|c|}{ Appendix 2. Cultural Dimension Survey Questions } \\
\hline No & Variables & Questions & $M$ & $S D$ \\
\hline \multirow{5}{*}{1} & \multirow{5}{*}{$\begin{array}{l}\text { Uncertainty } \\
\text { Avoidance }\end{array}$} & $\begin{array}{c}\text { It is important to have instructions spelled out in detail so that I always know what I am } \\
\text { expected to do }\end{array}$ & 4.72 & 0.64 \\
\hline & & It is important to closely follow instructions and procedures. & 4.71 & 0.61 \\
\hline & & Rules and regulations are important because they inform me aboutwhat is expected of me. & 4.68 & 0.66 \\
\hline & & Standardized work procedures are helpful. & 4.71 & 0.64 \\
\hline & & Instructions for operations are important. & 4.77 & 0.53 \\
\hline \multirow{6}{*}{2} & \multirow{6}{*}{ Collectivism } & Individuals should sacrifice their self-interest for the group. & 3.39 & 1.09 \\
\hline & & Individuals should stick with the group despite difficulties. & 3.51 & 1.25 \\
\hline & & Group welfare is more important than individual reward. & 3.69 & 1.19 \\
\hline & & Group success is more important than individual success. & 3.56 & 1.21 \\
\hline & & Individuals should only pursue their goals after considering the welfare of the group. & 2.64 & 1.19 \\
\hline & & Group loyalty should be encouraged even if individual goals suffer. & 3.24 & 1.28 \\
\hline \multirow{6}{*}{3} & \multirow{6}{*}{$\begin{array}{l}\text { Long-term } \\
\text { Orientation }\end{array}$} & Careful management of money (thrift) & 4.64 & 0.75 \\
\hline & & Going on resolutely in spite of opposition (persistence) & 4.15 & 1.02 \\
\hline & & Personal steadiness and stability & 4.57 & 0.71 \\
\hline & & Long-term planning & 4.63 & 0.73 \\
\hline & & Giving up today's fun for futuresuccess & 4.09 & 1.14 \\
\hline & & Working hard for success in the future & 4.77 & 0.51 \\
\hline
\end{tabular}

